\title{
Palliative sedation for terminally ill cancer patients in a tertiary cancer center in Shanghai, China
}

\author{
Xiaoli Gu ${ }^{1,2}$, Wenwu Cheng ${ }^{1,2^{*}}$, Menglei Chen ${ }^{1,2}$, Minghui Liu ${ }^{1,2}$ and Zhe Zhang ${ }^{1,2}$
}

\begin{abstract}
Background: There are a number of studies dedicated to characteristics of sedation, but these studies are mostly bound to western country practices. The aim of this study is to describe the characteristics of patients who suffered from cancer and who had been sedated until their death in Shanghai, China.

Methods: Retrospective medical data of 244 terminally ill cancer patients including 82 sedated patients were collected. Data collected included demographic characteristics, disease-related characteristics and details of the sedation.

Results: In sedated cases, patients and/or caregivers gave the consent to start palliative sedation due to unmanageable symptoms. On average, sedation was performed 24.65( \pm 1.78$)$ hours before death. Agitated delirium and dyspnea were the most frequent indications for palliative sedation. There was no significant difference in survival time from admission till death between sedated and non-sedated patients ( $p>0.05)$.

Conclusions: Palliative sedation is effective for reducing terminally ill cancer patients' suffering without hastening death. Prospective research is needed to determine the optimal conditions for Chinese patients including indications, decision making process, informed consent, cultural and ethical issues, type of sedation and drugs.
\end{abstract}

Keywords: Palliative sedation, Terminally ill cancer patients, Survival, End of life, Symptom management, Agitated delirium

\section{Background}

Mini abstract

Palliative sedation is effective for reducing the suffering of terminally ill cancer patients without hastening death. Agitated delirium and dyspnea were the most frequent indications for palliative sedation.

Terminally ill cancer patients may suffer severe refractory symptoms in their last weeks of life despite having received palliative treatments. Palliative sedation (PS) is one of the optimal palliative therapies used for these patients who are resistant to any other forms of treatments $[1,2]$. According to the definition proposed by the National Hospice and Palliative Care Organization (NHPCO), PS is the lowering of patients' consciousness using medications for the express purpose of limiting patients' awareness of suffering that is intractable and intolerable, or sufferings that patients perceive to be unbearable, which has not adequately respond to any interventions and for which

\footnotetext{
* Correspondence: wenwucheng@yahoo.com

'Department of Integrated Therapy, Fudan University Shanghai Cancer Center, \#270, Dong'An Road, Shanghai 200032, People's Republic of China ${ }^{2}$ Department of Oncology, Shanghai Medical College, Fudan University, \#270, Dong'An Road, Shanghai 200032, China
}

additional interventions are either unavailable or impractical [3]. PS can be performed intermittently or continuously until death, and that the depth of sedation can vary from a lower level of consciousness to complete unconsciousness.

PS is frequently used in end-of-life care for terminally ill cancer patients in Western countries. Guidelines and recommendations have been published by different organizations according to different cultural backgrounds and practices such as NHPCO, European Association for Palliative Care(EAPC), the Royal Dutch Medical Association [4-6]. Several inconsistencies exist amongst the guidelines with regards to the initiation, the level, the pattern and even the continuation or discontinuation of life-sustaining therapies. These discrepancies can be attributed to divergent PS definitions, ethical and clinical factors in different areas $[7,8]$.

China is a traditional East Asian country with a unique view on end-of-life issues [9]. Traditional Chinese culture dictates that a good death can only be obtained if consciousness is kept clear near the end of life. For Chinese patients and their families, they may be concerned about the doctrine of double effects of PS. PS 
may also be confused with euthanasia and physicianassisted suicide because of its potential life-shortening effect. Therefore, it is challenging to follow the western recommendations for palliative care while taking into account the differences in Chinese culture.

There are currently no guidelines or any other rules for PS for Chinese cancer patients. There are not even any formal studies of PS for terminally ill cancer patients. Thus, we present an analysis of PS practice from a Tertiary Metropolitan Cancer Center in Shanghai, China. This study aims to summarize the characteristics of patients who were sedated for refractory symptoms and describe and reflect on some different practices in Mainland China.

\section{Methods}

Palliative sedation policy and decision making process in the department

Fudan University Shanghai Cancer Center (FUSCC) is an 800-bed tertiary cancer center. The Integrated Therapy Department (used called Palliative Care Department) with a 12-bed inpatient ward was established in 2006 to provide supportive care for advanced cancer patients who cannot undergo any anti-cancer therapy. In this department, daily multidisciplinary meetings are held with palliative care physicians, medical oncologists, nurses, and weekly meetings with an anesthesiologist, a psychiatrist, and social workers.

The sedation was performed according to the sedation routine of our department, which was established through previous experience and clinical research [10], and is described below. PS was potentially indicated for patients with refractory physical symptoms. Initially, intermittent sedation was used. The decision to transition from intermittent to continuous sedation for these patients was based on the prevalence of uncontrolled symptoms. Once PS was implemented, the patients' vital signs were monitored by nurses regularly during the initial 24 hours. Cessation of sedation was considered when the symptoms became manageable. The indications to start PS, the drugs used for and the duration of the sedation, the decision-making process were recorded in patients' medical records.

Every patient admitted to the in-patient department of the FUSCC has the option to sign a letter of authorization giving family members the right to make medical decisions for him should he lose his decision-making capacities. For patients lacking decisional capacities, permission was obtained from a legal proxy. The decision-making process for PS was undertaken by a multi-professional palliative care team with more than 3 senior attending palliative physicians to discuss whether PS would ease the patients' sufferings. PS was recommended by a patients' attending physician according to the patients' symptom sufferings and estimated survival length time. A written informed consent form was signed when physicians and patients and/or authorized family members reached an agreement to implement PS after the aims, benefits and risks of PS were informed to patients and/or authorized family. After the written informed consent form was signed by the patients and/or authorized family, sedation drugs were prescribed by the patients' attending physician.

\section{Patients and measurements}

This study was approved by the Institutional Review Board of the Cancer Center. A systematic retrospective analysis was performed of the medical records of those who died in the Integrated Therapy Department in FUSCC between March 2007 and September 2011.

We reviewed the medical records of the 244 patients through the Union Medical System (UMS) of FUSCC. (The UMS is the electronic medical records system which containing all the medical information of patients in the FUSCC.) Three physicians reviewed the medical records of patients to select patients who received PS for the purpose of palliation. Patients who received benzodiazepines (such as estazolam) for insomnia as symptom control were excluded from this research. Our unit did not use PS for management of anxiety or existential suffering alone.

Demographic variables and details of PS of these patients were gathered and reviewed. The demographic variables included sex, age, diagnosis, metastatic sites and functional/performance status at the day of admission as measured by using the Karnofsky Performance Scale (KPS) ranging from 100 (normal) to 0 (dead).The details of sedation records included the indication to start PS, the duration of the PS, the sub-type of PS, drugs and dosage used, and the administration route of PS. The duration of PS was defined as the number of hours elapsed between the start of PS until it was stopped or the patients died. The sub-type of PS was intermittent or continuous sedation. Survival time was defined as the time between the day of admission to the hospital and the day patients died. The total survival time was defined as the time between the day patients were diagnosed and the day patients died.

The informed consent forms were retrieved through the UMS to evaluate the decision-making process of patients and their family caregivers.

\section{Statistical analysis}

Data management and statistical analysis were performed using SPSS 16.0 software. Frequency distributions were used to describe the demographic data and the distribution of each variable. A Chi-squared test was used to make comparisons with respect to categorical variables, and Fisher's exact test was used if sample size criteria were not met for Chi-squared approximation. 
The Kaplan-Meier and Log-rank test were used to compare the survival time between sedated and non-sedated patients. A p-value less than 0.05 was considered statistically significant.

\section{Results}

\section{Demographic and survival differences between sedated} and non-sedated patients

General characteristics of enrolled patients are shown in Table 1. 244 terminally ill cancer patients were included in this study. $51.23 \%$ were men. The median age was 63 years old (range 24 to 93 years old). Lung cancer was the most common diagnosis (14.8\%). 156 of 244 (63.93\%) patients had metastasis. Lung, liver and bone were the most prevalent metastatic sites, and 55 patients $(22.54 \%)$ had more than 3 sites of metastasis. The most frequent KPS was 20, indicating that patients were mainly

Table 1 Demographic and survival difference between sedated and non-sedated patients

\begin{tabular}{|c|c|c|c|c|}
\hline Variables & Total & $\begin{array}{l}\text { Sedated } \\
(N=82)\end{array}$ & $\begin{array}{l}\text { Non-sedated } \\
(N=162)\end{array}$ & $P$ value \\
\hline Total & 244 & 82 & 162 & - \\
\hline Mean age (years) & 63 & 62 & 63 & 0.86 \\
\hline Gender (male/female) & $\begin{array}{l}125 / \\
119\end{array}$ & $40 / 42$ & $85 / 77$ & 0.34 \\
\hline KPS (median) & 20 & 20 & 30 & 0.12 \\
\hline $\begin{array}{l}\text { Primary tumor } \\
\text { site (N/\%) }\end{array}$ & & & & 0.60 \\
\hline Lung cancer & 36 & $12 / 14.6 \%$ & $24 / 14.8 \%$ & \\
\hline Liver cancer & 30 & $12 / 14.6 \%$ & $18 / 11.1 \%$ & \\
\hline Breast cancer & 26 & $8 / 9.8 \%$ & $18 / 11.1 \%$ & \\
\hline Stomach cancer & 33 & $9 / 11.0 \%$ & $24 / 14.8 \%$ & \\
\hline Colon cancer & 22 & $8 / 9.8 \%$ & $14 / 8.6 \%$ & \\
\hline $\begin{array}{l}\text { Nasopharyngeal } \\
\text { cancer }\end{array}$ & 6 & $2 / 2.4 \%$ & $4 / 2.5 \%$ & \\
\hline $\begin{array}{l}\text { Kidney/Prostate } \\
\text { cancer }\end{array}$ & 17 & $5 / 6.1 \%$ & $12 / 7.4 \%$ & \\
\hline Pancreas & 20 & $7 / 8.5 \%$ & $13 / 8.0 \%$ & \\
\hline Gallbladder & 9 & $3 / 3.7 \%$ & $6 / 3.7 \%$ & \\
\hline $\begin{array}{l}\text { Hematological } \\
\text { Cancer }\end{array}$ & 4 & $2 / 2.4 \%$ & $2 / 1.2 \%$ & \\
\hline $\begin{array}{l}\text { Female genital tract } \\
\text { cancer }\end{array}$ & 20 & $8 / 9.8 \%$ & $12 / 7.4 \%$ & \\
\hline Primary unknown & 7 & $2 / 2.4 \%$ & $5 / 3.1 \%$ & \\
\hline Others & 12 & $2 / 2.4 \%$ & $10 / 6.2 \%$ & \\
\hline $\begin{array}{l}\text { Survival time (days) } \\
\text { (mean) }(95 \mathrm{Cl})^{*}\end{array}$ & 23.54 & $\begin{array}{l}27.44(23.2- \\
31.65)\end{array}$ & $\begin{array}{l}21.56(18.52- \\
24.59)\end{array}$ & 0.066 \\
\hline $\begin{array}{l}\text { Total Survival time } \\
\text { (months)(mean) } \\
(95 \mathrm{Cl}) \#\end{array}$ & 25.86 & $\begin{array}{l}35.65(26.55- \\
44.75)\end{array}$ & $\begin{array}{l}20.90(16.72- \\
25.10)\end{array}$ & 0.002 \\
\hline
\end{tabular}

* Survival time means the days since administration till death. \# Total Survival time means the months since diagnose till death. bedbound and required assistance with care. The mean survival time was 23.54 days (95\% CI: 22,27 ), the median survival time was 19 days (95\% CI: 17, 21), and the range was $1-139$ days.

There were no differences between sedated and nonsedated patients in gender, age, and primary cancer sites. The median KPS of the sedated patients was lower than that of non-sedated patients (20 and 30, respectively), but the difference was not significant $(p>0.05)$. The similar characteristics of the sedated and non-sedated patients indicated that the survival difference of the two groups could be compared. The sedated patients had a mean survival time of 27.44 days while the non-sedated patients had a mean survival time of 21.56 days. There was no statistically significant difference between the survival time of the two groups $(p=0.066)$. Sedated patients had a significantly longer total survival time than non-sedated patients $(\mathrm{p}=0.002)$.

\section{Details of sedation}

The details of sedation are shown in Table 2. 54 out of $82(65.85 \%)$ patients began sedation 0-24 hours before death and 18 (21.95\%) patients began sedation 25-48 hours before death. On average, sedation began 24.65 hours ( $\mathrm{SD} \pm 1.78$, range: $2-71$ hours) before death. The median time was 22 hours. No patients stopped receiving sedation once the sedation had begun.

All 82 patients were intermittently sedated at the beginning, allowing minimal contact with relatives. 20 patients transferred from intermittent to continuous sedation between the start of sedation and death. The mean transfer point was 13.45 hours $(\mathrm{SD} \pm 13.5)$ before death. The most commonly used drugs were diazepam in 59 patients, haloperidol in 48 patients and chlorpromazine in 9 patients. 34 patients used more than one kind of drug.

Diazepam and haloperidol were used for intermittent PS. Chlorpromazine was used for intermittent PS or in combination with other drugs for continuous PS. Morphine was used in combination with other drugs for 12 of the 82 sedated patients. The most frequent route of administration was intramuscular injection.

Agitated delirium and dyspnea were the most frequent indications for starting PS. 39 received sedation for agitated delirium, 35 for dyspnea, and 12 patients for uncontrolled pain.

\section{Decision making}

All 82 patients had signed the letter of authorization at admission. In 65 cases only the caregivers' consent was received. This was frequently related to cognitive impairment of various etiologies. Communication was no longer possible or was reduced to the most basic issues with these patients. In 7 cases only the patient's consent 
Table 2 Details of palliative sedation in 82 patients

\begin{tabular}{|c|c|}
\hline Variables & $\mathrm{N}$ \\
\hline \multicolumn{2}{|l|}{ Frequency of palliative sedation (N/\%) } \\
\hline Intermittently & $82(100 \%)$ \\
\hline Intermittently to continuously & 20 \\
\hline \multicolumn{2}{|l|}{ Medication for sedation* } \\
\hline Diazepam & 59 \\
\hline Haloperidol & 48 \\
\hline Chlorpromazine & 9 \\
\hline \multicolumn{2}{|l|}{ Route ※ } \\
\hline Intravenous injection & 3 \\
\hline Intramuscular injection & 81 \\
\hline \multicolumn{2}{|l|}{ Sedation Duration } \\
\hline Mean hour (SD) & $24.65( \pm 1.78)$ \\
\hline Median hour (range) & $22(2-71)$ \\
\hline \multicolumn{2}{|l|}{ Time between the start of sedation and death } \\
\hline $0-24$ hours before death $(\%)$ & $54(65.85 \%)$ \\
\hline 24-48 hours before death (\%) & $18(21.95 \%)$ \\
\hline$>48$ hours before death (\%) & $10(12.20 \%)$ \\
\hline \multicolumn{2}{|l|}{ Symptom indication for request (\%) \# } \\
\hline Agitated Delirum & 39 \\
\hline Dyspnea & 35 \\
\hline Pain & 12 \\
\hline others & 9 \\
\hline \multicolumn{2}{|l|}{ Consent } \\
\hline Caregivers consent only & 65 \\
\hline Patientss' consent only & 7 \\
\hline Both the caregivers and patients consent & 10 \\
\hline
\end{tabular}

* 34 patients used more than one kind of drugs.

* The number in the route was 84 because 2 patients received both intravenous and intramuscular injection.

\#10 patients suffered more than one indication for the PS. Others included uncontrolled nausea and vomiting.

was obtained; in 10 cases both the patients' and caregivers' consents were received.

\section{Discussion}

This study provided the overview of the characteristics of PS implementation in Mainland China. Our study revealed that $33.6 \%$ of the patients who died in the Integrated Therapy Department received some form of PS. The cultural values of each society play an important role in shaping the practice of sedation according to different definitions, cultural understandings and traditions. This is reflected in several dimensions of the details of PS at FUSCC.

There was no statistically significant difference in survival time between patients who underwent sedation and those who did not. This indicated that PS had no potential life-shortening effect in consist with previous researches [11-15]. Sedation patients had a significantly longer total survival time than non-sedated patients in our study. This may be explained by that patients who had a longer disease journey suffered more and had the more desire to reduce the suffering.

In this study, the frequency of sedation was 33.6\% $(82 / 244)$, similar with a review enrolled 10 studies with 1807 patients (34.4\%) [2]. But our rate of PS is higher than that reported in a Taiwanese study more than 10 years ago $(27.9 \%)$ and in a Singaporean study $(22.6 \%$ at 48 hours before death) in 2012 [16,17]. Although the Taiwanese, Singaporeans and Mainland Chinese share a similar cultural background, the difference still exists. This difference can be explained by the large variability of PS frequency, which was reported as $1-88 \%$ according to cultural understanding of PS and different time period examined $[18,19]$.

The median duration of PS in our department was 22 hours, while the median time in previous studies varied from 21.6 to 48 hours [12,20-23]. $65.85 \%$ of our sedated patients died within 24 hours. The potential explanation for shorter duration and late initiation maybe was that patients were usually at the stage of impending death when they started to receive PS. From the physicians' perspective, estimating the patients' remaining survival time was considered to be a difficult and challenging task. From the patients and caregivers' perspective, sedation was seen as having a potential life-shortening effect. These reasons may have lead to PS being started too late and patients suffering needlessly at the end of life."

As found in other studies, agitated delirium and dyspnea were the most frequent symptom indications for PS [22-24]. Although delirium was consistently the most common indication for PS in other studies, there was wide variability in its occurrence as an indicator (ranging from 13.8\%-91.3\%) [2]. In our practice, for patients with agitated delirium, the underlying cause was treated first with re-balancing water and electrolytes and provision of psychological support. Nevertheless, 39 patients required sedation for uncontrolled terminal stage agitation in our research. In this study, the frequency of pain as the indicator was lower than reported in previous researches [25-27], because PS was used for pain only after failure of interventions including opioids switching and escalation and other adjuvant drugs in our department.

In this study, Diazepam, a kind of benzodiazepine, was the drug used most often for sedation. It was the first choice because midazolam, the most popular drug for PS in Western practice, is not available in our department $[28,29]$. The second most used drug, haloperidol was not in the list of recommended drugs for PS according to the EAPC and NHAPC guidelines, but in many studies, it was still the first choice for patients with 
unmanageable agitated delirium. Haloperidol was used in $26 \%$ of sedated patients according to the review of 10 studies which enrolled 1807 patients combined [2]. Morphine was also not included in the list of the recommended drugs, but it may have produced an effect alongside sedation.

Continuous palliative sedation is increasingly accepted as a part of palliative care therapy in many countries [30]. Studies show that continuous sedation was performed in $2.5 \%-15 \%$ of all deaths in Europe [31-34]. $8.2 \%(20 / 244)$ patients in our study received continuous sedation. The decision to switch from intermittent to continuous sedation for these patients was based on the prevalence of uncontrolled symptoms. This indicated that continuous sedation can be acceptable for Chinese patients after sufficient discussion with family caregivers in some situations. As interfering with the dying process by causing patients to become unconscious, even with the intent to relieve physical suffering, was viewed as inhumane in Chinese traditional society, these results reflect to some extent a shift in end-of-life values.

The decision-making process also reflected the cultural values of each society. The reported degree of involvement of and information given to patients and families varies considerably $[35,36]$. Autonomy is one of the most valued rights in Western countries, especially in the United States, while in Eastern countries, illness is considered a family event rather than an individual occurrence [37]. Previous studies revealed that Asian patients prefer to leave end-of-life decisions to their family caregivers [38]. The family caregivers played a more important role in the decision-making process than patients. Liu JM's research found that Chinese patients are less likely to sign their own do-not-resuscitate (DNR) orders [39]. The reason is that according to cultural tradition in China, the individual is viewed as embedded in the family and society. The decision making process for PS in our department is in accordance with this phenomenon. In our research, when patients were not conscious enough to make the decision for PS, we obtained informed consent only from their caregivers. Although to some extent, decisions from caregivers reflected the wishes of the patients, there was still potential for an ethical conflict when therapeutic decisions had to be made for these patients [35].

The key drawback of this study was that the retrospective research method had some limitations. Firstly, there were no standard form to record details of PS. Secondly, the information about the assessment of the symptom relief after receiving PS was insufficient to analyze. Another limitation is that as the data we gathered was in one cancer center, the result of this study cannot be extrapolated to other care settings in mainland China. To reduce the bias, studies involving multiple centers should be carried out in the future.

\section{Conclusion}

To our knowledge, this research is the first study focused on the practice of PS for terminally ill cancer patients in mainland China. We recognized that PS is effective for reducing the suffering of these patients without hastening death. Prospective research is needed to determine the optimal conditions for Chinese patients including indications, decision making process, informed consent, cultural and ethical issues, type of sedation and drugs.

\section{Competing interest}

The authors have no conflicts of interest to declare. This study has no financial relationship with any organization that sponsored the research and authorship. The corresponding author has full control of all primary data and will allow the journal to review the data if requested.

\section{Authors' contributions}

XLG drafted the paper and performed the main statistical analyses. WWC supervised the study, reviewed the analysis, and revised the manuscript. All authors contributed to study design. MLC and MHL reviewed the charts, collected the data, and analysed the qualitative data. ZZ provided extensive background knowledge and participated in the discussion of the results. All authors read, approved and contributed to the final paper. WWC takes responsibility for the manuscript.

\section{Acknowledgement}

We are very grateful for the participation of patients, carers, physicians and nurses at Department of Integrated Therapy, Fudan University Shanghai Cancer Center.

Received: 19 August 2014 Accepted: 20 February 2015

Published online: 15 March 2015

\section{References}

1. Howland J. Questions about palliative sedation: An act of mercy or mercy killing? Ethics Medics. 2005;30:1-2.

2. Maltoni M, Scarpi E, Rosati M, Derni S, Fabbri L, Martini F. Palliative sedation in end-of-life care and survival: A systematic review. J Clin Oncol. 2012;30:1378-83.

3. Kirk TW, Mahon MM. Palliative Sedation Task Force of the National Hospice and Palliative Care Organization Ethics Committee: National hospice and palliative care organization (NHPCO) position statement and commentary on the use of palliative sedation in imminently dying terminally ill patients. J Pain Symptom Manage. 2010;39:914-23.

4. Cherny NI, Radbruch L. Board of the European Association for Palliative Care: European association for palliative care (EAPC) recommended framework for the use of sedation in palliative care. Palliat Med. 2009;23:581-93.

5. De Graeff A, Dean M. Palliative sedation therapy in the last weeks of life: A literature review and recommendations for standards. J Palliat Med. 2007:10:67-85.

6. Pasman HR, Wolf JE, Hesselink BA, van der Heide A, van der Wal G, van der Maas PJ, et al. Policy statements and practice guidelines for medical end-oflife decisions in Dutch health care institutions: developments in the past decade. HealthPolicy. 2009:92:79-88.

7. Claessens P, Menten J, Schotsmans P, Broeckaert B. Palliative sedation: A review of the research literature. J Pain Symptom Manage. 2008;36:310-33.

8. Fainsinger RL, Waller A, Bercovici M, Bengtson K, Landman W, Hosking M, et al. A multicentre international study of sedation for uncontrolled symptoms in terminally ill patients. Palliat Med. 2000;14:257-65.

9. Feldman MD, Zhang J, Cummings SR. Chinese and U.S. Internists Adhere to Different Ethical Standards. J Gen Intern Med. 1999:14:469-73.

10. Xiaoli G, Wenwu C. Palliative sedation for terminally ill cancer patients. China oncology. 2010;20:695-8.

11. Alonso-Babarro A, Varela-Cerdeira M, Torres-Vigil I, Rodríguez-Barrientos R, Bruera E. At-home palliative sedation for end-of-life cancer patients. Palliat Med. 2010;24:486-92. 
12. Maltoni M, Pittureri C, Scarpi E, Piccinini L, Martini F, Turci P, et al. Palliative sedation therapy does not hasten death: Results from a prospective multicenter study. Ann Oncol. 2009;20:1163-9.

13. Kohara H, Ueoka H, Takeyama H, Murakami T, Morita T. Sedation for terminally ill patients with cancer with uncontrollable physical distress. J Palliat Med. 2005:8:20-5.

14. Morita T, Tsunoda J, Inoue S, Chihara S. Effects of high dose opioids and sedatives on survival in terminally ill cancer patients. J Pain Symptom Manage. 2001;21:282-9.

15. Vitetta L, Kenner D, Sali A. Sedation and analgesia-prescribing patterns in terminally ill patients at the end of life. Am J Hosp Palliat Care. 2005;22:465-73.

16. Chiu TY, Hu WY, Lue BH, Cheng SY, Chen CY. Sedation for refractory symptoms of terminal cancer patients in Taiwan. J Pain Symptom Manage. 2001;21:467-72.

17. Krishna LKR, Poulose VJ, Goh C. The use of midazolam and haloperidol in cancer patients at the end of life. Singapore Med J. 2012;53:62-6.

18. Turner K, Chye R, Aggarwal G, Philip J, Skeels A, Lickiss JN. Dignity in dying: A preliminary study of patients in the last three days of life. J Palliat Care. 1996;12:7-13.

19. Fainsinger RL. Use of sedation by a hospital palliative care support team. J Palliat Care. 1998;14:51-4.

20. Sykes N, Thorns A. Sedative use in the last week of life and the implications for end-of-life decision making. Arch Intern Med. 2003;163:341-4.

21. Sykes N, Thorns A. The use of opioids and sedatives at the end of life. Lancet Oncology. 2003;4:312-8.

22. Rietjens JA, van Zuylen $L$, van Veluw $H$, van der Wijk $L$, van der Heide A, van der Rijt CC. Palliative sedation in a specialized unit for acute palliative care in a cancer hospital: Comparing patients dying with and without palliative sedation. J Pain Symptom Manage. 2008;36:228-34.

23. Mercadante S, Intravaia G, Villari P, Ferrera P, David F, Casuccio A. Controlled sedation for refractory symptoms in dying patients. J Pain Symptom Manage. 2009;37:771-9.

24. Fainsinger RL, Miller MJ, Bruera E, Hanson J, Maceachern T. Symptom control during the last week of life on a palliative care unit. J Palliat Care. 1997;7:5-11.

25. Stone P, Phillips C, Spruyt O, Waight C. A comparison of the use of sedatives in a hospital support team and in a hospice. Palliat Med. 1997;11:140-4.

26. Fainsinger RL, Landman W, Hoskings M, Bruera E. Sedation for uncontrolled symptoms in a South African hospice. J Pain Symptom Manage. 1998;16:145-52.

27. Ventafridda V, Ripamonti C, De Conno F, Tamburini M, Cassileth BR. Symptom prevalence and control during cancer patients' last days of life. J Palliat Care. 1990;6:7-11.

28. Bruinsma SM, Rietjens JA, Seymour JE, Anquinet $L$, Van der Heide A. The experiences of relatives with the practice of palliative sedation: A systematic review. J Pain Symptom Manage. 2012;44:431-45.

29. Jaspers B, Nauck F, Lindena G, Elsner F, Ostgathe C, Radbruch L. Palliative Sedation in Germany: How Much Do We Know? A Prospective Survey. J Palliat Med. 2012;15:672-80

30. Juth N, Lindblad A, Lynöe N, Sjöstrand M, Helgesson G. European association for palliative care (EAPC) framework for palliative sedation: An ethical discussion. BMC Palliat Care. 2010;13:20.

31. Seale C. End-of-life decisions in the UK involving medical practitioners. Palliat Med. 2009;23:198-204.

32. Claessens P, Menten J, Schotsmans P, Broeckaert B. Palliative sedation, not slow euthanasia: A prospective, longitudinal study of sedation in Flemish palliative care units. J Pain Symptom Manage. 2011;41:14-24.

33. Miccinesi G, Rietjens JA, Deliens L, Paci E, Bosshard G, Nilstun T, et al. Continuous deep sedation: Physicians' experiences in six european countries. J Pain Symptom Manage. 2006;31:122-9.

34. Inghelbrecht E, Bilsen J, Mortier F, Deliens L. Continuous deep sedation until death in belgium: A survey among nurses. J Pain Symptom Manage. 2011:41:870-9.

35. Mercadante S, Porzio G, Valle A, Fusco F, Aielli F, Adile C, et al. Palliative sedation in advanced cancer patients followed at home: A retrospective analysis. J Pain Symptom Manage. 2009;43:1126-30.

36. Vayne-Bossert $P$, Zulian GB. Palliative sedation: From the family perspective. Am J Hosp Palliat Care. 2013;30:786-90.
37. Curtis JR. International perspectives on intensive care at the end-of-life. Crit Care. 2003;7:95-6.

38. Bowman KW, Singer PA. Chinese seniors' perspectives on end-of-life decisions. Soc Sci Med. 2001;53:455-64.

39. Liu JM, Lin WC, Chen YM, Wu HW, Yao NS, Chen LT, et al. The status of the do-not-resuscitate order in Chinese clinical trial patients in a cancer centre. Med Ethics. 1999;25:309-14.

\section{Submit your next manuscript to BioMed Central and take full advantage of:}

- Convenient online submission

- Thorough peer review

- No space constraints or color figure charges

- Immediate publication on acceptance

- Inclusion in PubMed, CAS, Scopus and Google Scholar

- Research which is freely available for redistribution

Submit your manuscript at www.biomedcentral.com/submit 